\title{
Review
}

\section{Responses of root-feeding nematodes (Helicotylenchus spp.) to local and non-local populations of the host plant Ammophila arenaria}

\author{
Catarina Schreck Reis ${ }^{a, *}$, Helena Freitas ${ }^{a}$, Wim H. van der Putten ${ }^{b, c}$ \\ ${ }^{a}$ Centre for Functional Ecology, Department of Botany, University of Coimbra, Calçada Martim de Freitas, \\ 3000-456 Coimbra, Portugal \\ ${ }^{\mathrm{b}}$ Netherlands Institute of Ecology (NIOO-KNAW), Department of Multitrophic Interactions, Boterhoeksestraat 48, \\ PO Box 40, 6666 ZG, Heteren, The Netherlands \\ ${ }^{\mathrm{c}}$ Laboratory of Nematology, Wageningen University and Research Centre, PO Box 8123, 6700 ES Wageningen, The Netherlands
}

\section{A R T I C L E I N F O}

Article history:

Received 9 November 2007

Received in revised form

15 January 2008

Accepted 18 January 2008

\section{Keywords:}

Coastal sand dunes

Helicotylenchus n. sp.

Helicotylenchus pseudorobustus

Marram grass

Plant-nematode interactions

Host specificity

\begin{abstract}
A B S T R A C T
The root-feeding nematode community of wild plants may vary throughout their natural range. Little is known about how the variation of wild plants along their range affects their relationship with root-feeding nematodes. In the present study, we examined local and nonlocal combinations of host plants and root-feeding nematodes to test the hypothesis that nematode reproduction is favoured by local hosts. In two indoor experiments, we exposed populations of the wild dune grass Ammophila arenaria from northern and southern European coastal sand dunes to plant parasitic nematode species (Helicotylenchus spp.) from those same geographical origins. First, we used the southern nematode species to determine whether the effect of a local versus a non-local host may depend on nematode density. Then, in a cross-inoculation experiment we investigated how both nematode species performed with their local, as compared to the non-local hosts.

In both experiments, plant biomass and ontogenetic characteristics were not significantly different between the northern and southern populations. The applied nematode densities did not have a negative impact on plant performance. This allowed us to consider the response of the two different nematode species and their host plants without co-varying differences in plant responses. Reproduction of the nematode species differed according to host origin, but contrary to what we expected, nematode species did not perform better on their local hosts. Helicotylenchus n. sp., the southern species originating from Portugal, performed better on the non-local than on the local host. Male to female ratios were significantly different between the two nematode populations and were lowest in Helicotylenchus pseudorobustus from The Netherlands. Female and juveniles percentages were also quite distinct, with more females in the nematode species from The Netherlands and more juveniles in the nematode species from Portugal.

We concluded that ectoparasitic root-feeding nematodes Helicotylenchus spp. do not necessarily perform best on their local host population of the foredune grass A. arenaria. Our results imply that the natural distribution of Helicotylenchus spp. along the European
\end{abstract}

\footnotetext{
* Corresponding author. Tel.: +351 239 855210; fax: +351 239855211.

E-mail address: cschreckreis@ci.uc.pt (C. Schreck Reis). 
coast is determined by other factors than host populations. These other factors that could be abiotic, e.g. water availability, or biotic, e.g. local natural enemies adapted to Helicotylenchus spp. Introducing plant genotypes from other parts of the natural range will, therefore, not necessarily lead to reduced abundance of semi-endo or ectoparasitic root-feeding nematodes.

(C) 2008 Elsevier B.V. All rights reserved.

\section{Contents}

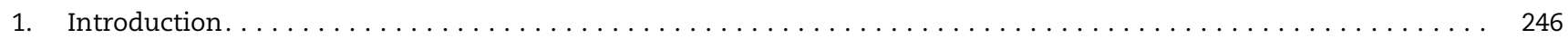

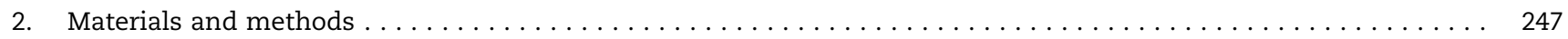

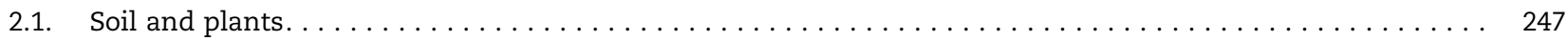

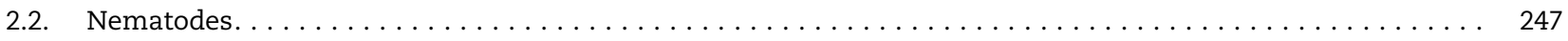

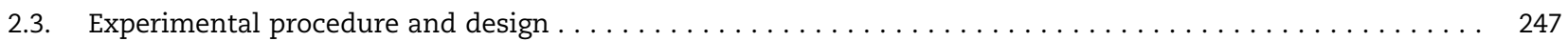

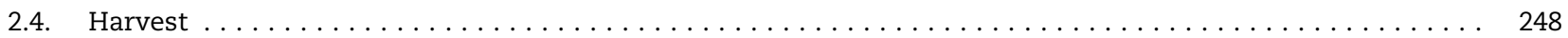

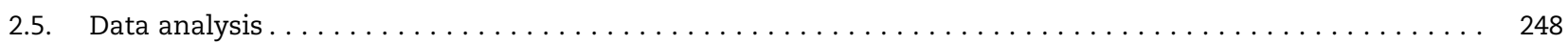

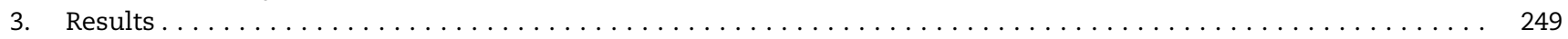

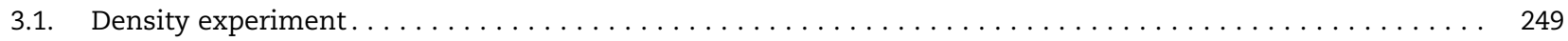

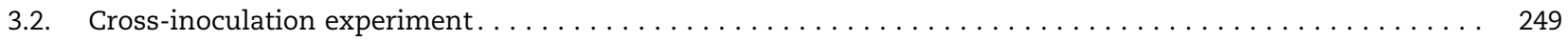

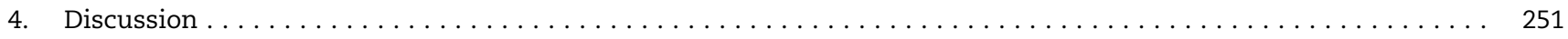

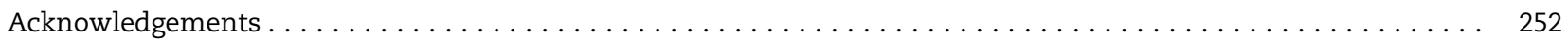

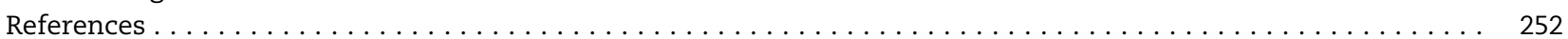

\section{Introduction}

Nematodes are a major component of the soil fauna (Wall et al., 2002). In natural soils nematodes are usually studied for their role in soil system processes and as indicators of soil quality (Bongers, 1990; Schloter et al., 2003), whereas in agricultural soils, most attention is given to those root-feeding nematodes, which are major crop pests. In spite of the many studies on host range of root-feeding nematodes in crops, these interactions largely result from human interferences, such as crop breeding and moving crop seeds within and between geographic ranges. Natural ecosystems provide interesting opportunities to study how host plant ranges may overlap with naturally co-occurring root-feeding nematodes and how local nematode populations or species respond to non-local plant populations.

An increasing number of studies in natural ecosystems is focusing on coastal sand dunes as a model system for interactions between wild host plants and their natural root-feeding nematodes (Yeates, 1967; Seliskar and Huettel, 1993; de Rooij-van der Goes, 1995; Little and Maun, 1997; van der Putten and van der Stoel, 1998; Orselli and Vinciguerra, 2000; van der Stoel et al., 2002; Wall et al., 2002;). Ammophila arenaria (L.) Link is a dominant pioneer grass in foredunes where it shows an unmatched capacity for dune formation and sand stabilization. It occurs naturally from north-western Europe along the Mediterranean coast (Huiskes, 1979), but it has a worldwide distribution since it was introduced in North America, South Africa, Australia and New Zealand. Along the European coast, there are two A. arenaria subspecies, A. arenaria ssp. arenaria in the north and A. arenaria ssp. arundinacea in the south, which can be distinguished morphologically (Huiskes, 1979; Fernández Prieto et al., 1987). There are molecular differences between these subspecies, as well as between populations within subspecies (RodríguezEcheverría et al., 2008).

The presence of plant parasitic nematodes varies along the natural distribution range of $\mathrm{A}$. arenaria. Some nematode genera occur as one species along part or the entire range, whereas others include several species, some of which have a more northern and others a more southern distribution (van der Putten et al., 2005). Within Europe, differences in density, diversity and species composition of nematode communities vary considerably (van der Putten and Troelstra, 1990; de Rooij-van der Goes et al., 1995; Orselli and Vinciguerra, 2000; van der Stoel et al., 2002; Schreck Reis et al., 2005). Heterodera, Meloidogyne and Pratylenchus are the dominant nematode genera of A. arenaria in The Netherlands (van der Putten et al., 1990; Brinkman et al., 2004), whereas Helicotylenchus sp. was the most abundant nematode genus of the Portuguese $A$. arenaria (Schreck Reis et al., 2005).

The genus Helicotylenchus probably contains three species along the Atlantic, North Sea and Baltic coasts of Europe. We used two species from this genus to analyze host populationnematode species interactions. Plant parasitic nematodes belonging to the genus Helicotylenchus are common and widely distributed around plant roots, occurring in most soils samples of cultivated and uncultivated soils (Firoza and MaqBool, 1994). Helicotylenchus spp. are usually classified as ectoparasite (Seliskar and Huettel, 1993; Siddiqi, 2000; van der Putten et al., 2005) but they can also be considered as semiendoparasite (Yeates et al., 1993) and even migratory endoparasites (Yeates, 1984; Cook and Yeates, 1993). Most studies on Helicotylenchus have focused on cultivated soils and economic profit plants such as wheat, maize, cotton and sugar-cane (Mukhopadhyaya, 1974). Although Helicotylenchus pseudorobustus is present in southern Europe, and particularly in Portugal (Abrantes et al., 1978; Fortuner, 1984) it has only 
been found in sand dunes systems from The Netherlands, north-western Europe (de Rooij-van der Goes et al., 1995). Several other Helicotylenchus species occur in coastal sand dunes: $H$. depressus was found in New Zealand dunes (Yeates, 1967), H. multicinctus in Poland (Kisiel, 1970), H. pseudorobustus, $H$. digonicus and $H$. multicinus were the most abundant nematodes in roots of the North American beach grass Ammophila breviligulata (Seliskar and Huettel, 1993). Recently, a new Helicotylenchus species was found to be associated with A. arenaria from Portuguese coastal sand dunes (Schreck Reis et al., unpublished results).

The aim of the present work was to study the interactions between A. arenaria populations from northern and southern Europe and the two corresponding root-feeding Helicotylenchus species present in both sites. Different aspects are involved in the nematode-plant host relationship such as plant variety, plant age, nematode species, nematode race and environment factors (Barker and Olthof, 1976). More recent studies have focus on the nematode interactions concerning local adaptation between pathogens and hosts in natural systems (van der Putten et al., 2006). We tested the hypothesis that nematode reproduction would be influenced by host origin. We expected that reproduction of local plant parasitic nematodes would be better with the local host plant population than with a non-local population. As nematode density may influence reproduction (de Rooijvan der Goes, 1995), we examined host plant suitability at a range of nematode inoculation densities. We analyzed nematode performance by quantifying total numbers, numbers of males, females and juveniles. We expected that at higher inoculation densities intraspecific competition would lead to higher percentage of males (Yeates, 1987) and analyzed if these effects would be dependent on host plant origin.

In order to test our hypotheses, two experiments were set up in controlled indoor conditions. Multiplication capacity of nematode species from southern Europe in different densities was studied in a density experiment that also allowed to determine if the host plant performance can be affected by high nematode densities. The effect of host plant suitability on the two Helicotylenchus species, from northern and southern Europe, was analyzed in a completely cross-inoculation experiment.

\section{Materials and methods}

\subsection{Soil and plants}

Sand was collected from the top of the foredunes, close to A. arenaria plants, in the Natural Reserve of São Jacinto Dunes $\left(40^{\circ} 41^{\prime} \mathrm{N} 8^{\circ} 44^{\prime} \mathrm{W}\right)$, at the north of the Portuguese coast. Sand was sieved through a 0.5 mesh sieve and homogenized before being sterilized by autoclaving at $120^{\circ} \mathrm{C}$ for $1 \mathrm{~h}$.

Seeds of A. arenaria from Portugal were collected from the same site of sand collection. Seeds of A. arenaria from The Netherlands were collected at Oostvoorne $\left(51^{\circ} 52^{\prime} \mathrm{N} 04^{\circ} 04^{\prime} \mathrm{E}\right)$. Seeds were germinated in small pots, in a $16 \mathrm{~h} / 8 \mathrm{~h}$ light/dark regime and $25^{\circ} \mathrm{C} / 16^{\circ} \mathrm{C}$ day/night temperatures, with sterilized sand and 2 weeks after germination, each experimental pot was filled with $1 \mathrm{~kg}$ of sterilized sand of $10 \%$ (w/w) soil moisture and planted with three seedlings.

\subsection{Nematodes}

Helicotylenchus n. sp. from Portugal and H. pseudorobustus from The Netherlands were collected from the same dune sites as the plants. Both nematode species were reproduced in laboratory cultures on their local A. arenaria host plants growing in pots with sterilized dune sand. Nematodes from the Portuguese cultures were extracted from roots using the Baermann Funnel method (Hooper, 1986) and from sand using the tray method (Whitehead and Hemming, 1965). Nematodes of the cultures from The Netherlands were extracted from roots using the funnel-spray method and from sand using an Oostenbrink elutriator (Oostenbrink, 1960). For the experiments sand with roots plants from The Netherlands were sent to Portugal and nematode extraction followed the methods applied in Portugal, Baermann Funnel for roots and tray for sand. The nematode densities were established by counting numbers in three subsamples originating from homogenized suspensions, using a binocular microscope (40-100× magnification). The estimatives were performed in two different solutions for each origin, in $20 \mathrm{ml}$ suspensions from a total volume of $1000 \mathrm{ml}$ for Portuguese nematodes solutions and $700 \mathrm{ml}$ for The Netherlands nematodes solutions. The average and standard error numbers were, for Portugal: $183.3 \pm 6.9$ and $161.0 \pm 7.5$ and for The Netherlands: $34.3 \pm 2.9$ and $171.7 \pm 9.2$. The nematodes were inoculated from continuously homogenized suspensions and added to pots experiments by pippeting. Additional water was supplied to control, low and medium nematode density pots to adjust total water volume added to the pots. All the nematode inoculation and water adjustment was done with tap water.

\subsection{Experimental procedure and design}

The pots were placed in a climate chamber with a $16 \mathrm{~h} / 8 \mathrm{~h}$ light/dark regime and $25^{\circ} \mathrm{C} / 16^{\circ} \mathrm{C}$ day/night temperatures. Pots were watered twice a week with demineralized water and once in every 2 weeks with Hoagland nutrition solution. Every 2 weeks, pots were re-randomized to avoid position effects.

Experiment 1: Density trial. We tested the effects of three densities of the southern European Helicotylenchus n. sp. and a control without nematodes added on nematode multiplication and plant biomass growth. Two plant populations were used as host, the one from northern Europe and the one from southern Europe, the natural host. These treatments resulted in a two-factor experiment of four nematode densities (control, low, medium, and high) and two plant populations (A. arenaria from northern and southern Europe). The number of nematodes used for each treatment was: zero for control, 100 pot $^{-1}$ for low density, 500 pot $^{-1}$ for medium density and 1000 pot $^{-1}$ for high density. Every treatment was carried out in six replicates, except for the high nematode density treatment, that was carried out in five replicates.

Experiment 2: Cross-inoculation. We tested effects of host plant origin on nematode multiplication and host plant biomass. In this experiment, carried out in conjunction with 
experiment 1, we analyzed effects of nematode species (Helicotylenchus n. sp. and H. pseudorobustus), inoculum density (low and medium; nematode numbers are outlined above) and host plant origin (Portugal and The Netherlands) on nematode multiplication. All experimental treatments were carried out in six replicates. Treatments were encoded as: plants from Netherlands and nematodes from Portugal (Np), plants and nematodes from Netherlands (Nn), plants and nematodes from Portugal (Pp) and plants from Portugal and nematodes from Netherlands (Pn).

\subsection{Harvest}

Plants were harvested 16 weeks after the start of both experiments. For each pot, the number of tillers was counted and the length of the longest leaf was measured. Roots and shoots were separated and weighed fresh. All roots were used for nematode extraction by Baermann Funnel method and after that, as for the shoots, dried at $70{ }^{\circ} \mathrm{C}$ for $48 \mathrm{~h}$ and weighed. The sand from each pot was homogenized and nematodes were extracted by the Whitehead and Hemming tray method using a volume of $300 \mathrm{cc}^{3}$ of the total $1000 \mathrm{cc}^{3}$ present in every pot. All samples were stored at $4{ }^{\circ} \mathrm{C}$ prior to their analysis.

Nematodes were counted in $20 \mathrm{ml}$ water suspensions using a binocular microscope (40-100× magnification). Total numbers of Helicotylenchus spp. were quantified, as well as numbers of females, males and juveniles separately. Total number of
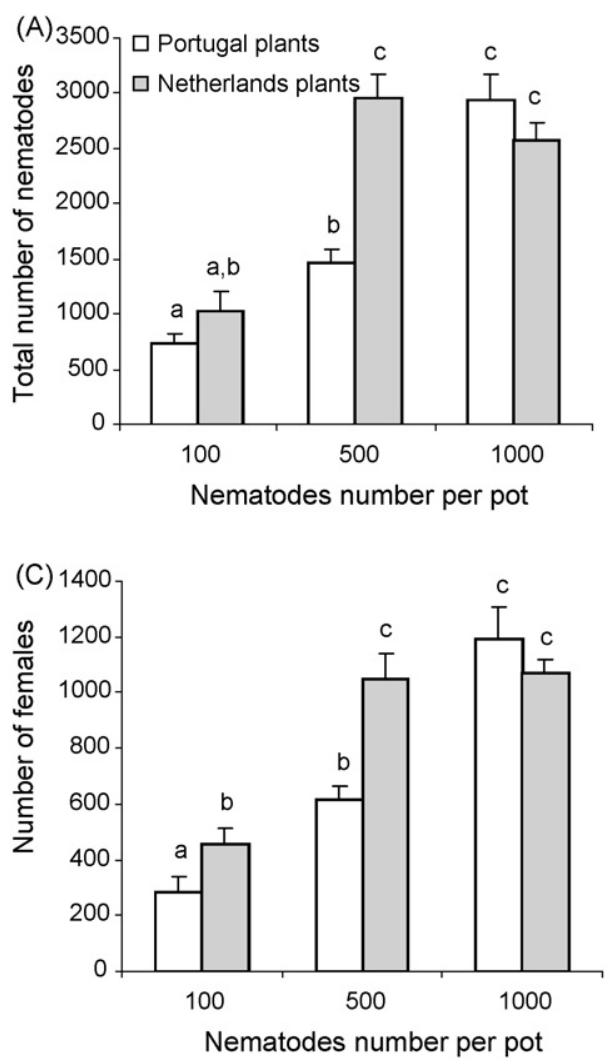

nematodes per pot was calculated by adding total numbers in roots and in the total sand volume. Data of non-plant feeders are not presented.

\subsection{Data analysis}

Statistical analysis was performed using Statistica 6.0 for Windows. Data were checked for normality using Kolmogorov-Smirnov test and for homogeneity using Bartlett's test. When assumptions failed, transformation of the data was performed by logarithmic or square root for nematode number and plant parameters and arcsine of the square root for percentage values, after dividing by 100 . As root dry weight did not achieve ANOVA assumptions, even not after transformations, non-parametric Kruskal-Wallis test was performed to test differences among treatments. Factorial two-way Anova was used to test differences for density experiment, with plant origin and nematode density as factors. Three-way ANOVAs were used to test differences in the cross-inoculation experiment, with nematode origin, nematode density and plant origin as factors. Treatment means within each factor were compared using Fisher's LSD test $(p<0.05)$.

The formula Pf/Pi, where Pf is final population density and $\mathrm{Pi}$ is initial population density was applied to nematode densities in order to determine the multiplication rate. Correlations were calculated between multiplication rate and initial nematode density for both experiments.
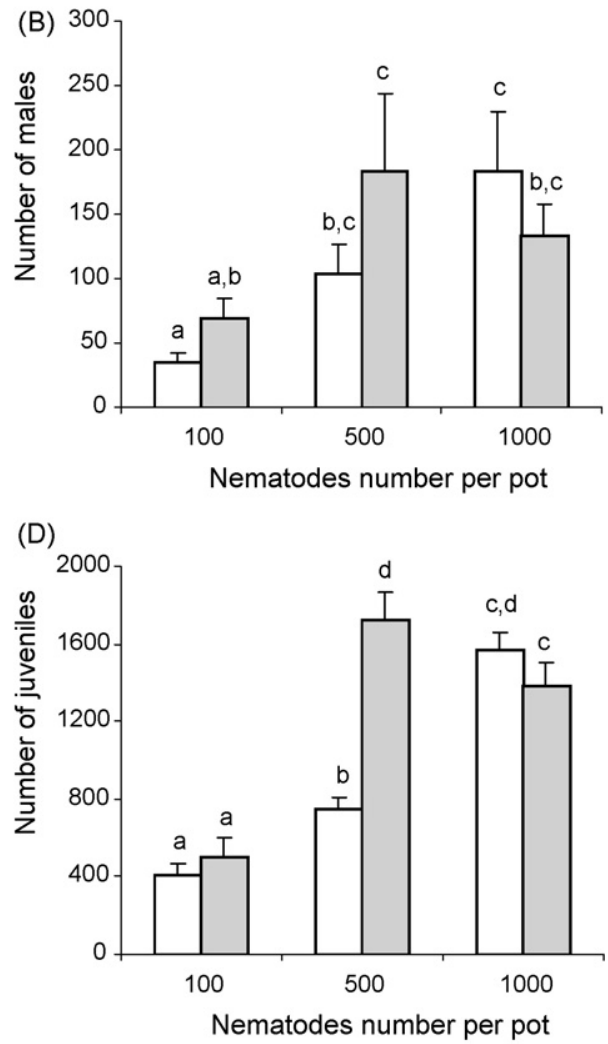

Fig. 1 - Final populations of total (A), males (B), females (C) and juveniles (D) of Helicotylenchus n. sp. from Portugal recovered on Ammophila arenaria plants from Portugal and The Netherlands 16 weeks after inoculation with 100,500 and 1000 nematodes per pot. Bars represent means + S.E. Different letters above bars indicate significant differences $(p<0.05)$ between treatments after two-way ANOVA and Fisher's test. 
Table 1 - Percentage of males, females and juveniles of Helicotylenchus $\mathbf{n}$. sp. from Portugal recovered on Ammophila arenaria plants from Portugal and The Netherlands 16 weeks after inoculation with 100, 500 and 1000 nematodes per pot

\begin{tabular}{lcccc} 
Plant origin & Nematode density & Males (\%) & Females (\%) $^{\mathrm{a}}$ & Juveniles (\%) $^{\mathrm{a}}$ \\
\hline Portugal & 0 & $0 \mathrm{a}$ & 50.0 & 50.0 \\
& 100 & $4.85 \mathrm{~b}$ & 38.8 & 56.4 \\
& 500 & $7.12 \mathrm{~b}$ & 41.9 & 50.9 \\
& 1000 & $6.25 \mathrm{~b}$ & 40.5 & 53.2 \\
Netherlands & 0 & $0 \mathrm{a}$ & 400 & $0 \mathrm{a}$ \\
& 100 & $6.72 \mathrm{~b}$ & 35.6 & $49.0 \mathrm{~b}$ \\
& 500 & $6.2 \mathrm{~b}$ & 41.5 & $58.2 \mathrm{c}$ \\
& 1000 & $5.18 \mathrm{~b}$ & $53.3 \mathrm{~b}, \mathrm{c}$ \\
\hline
\end{tabular}

Different letters indicate significant differences $(p<0.05)$ between treatments within plant populations after one-way Anova and Fisher test. No letters means no significant differences within plant origin.

\section{Results}

\subsection{Density experiment}

Reproduction of Helicotylenchus n. sp. was dependent on both nematode density and host origin when considering the total number of nematodes $(p=0.020)$, as well as for females $(p=0.041)$ and juveniles $(p=0.000)$. In all cases the effect of plant origin was considerably weaker than the nematode inoculation density ( $p=0.047$ vs. $p=0.000$ for total numbers of nematodes; $p=0.015$ vs. $p=0.000$ for females; $p=0.002$ vs. $p=0.000$ for juveniles, respectively). Numbers of male nematodes were influenced by inoculation density only $(p=0.000)$ (Fig. 1). The total number of Helicotylenchus n. sp. did not differ between plant origins, except that they were higher when inoculated as medium densities to A. arenaria plants from Netherlands than from Portugal (Fig. 1A). Nematode numbers increased with inoculation density from 0 to 6 in the control treatment, 510-1590 in low inoculation densities, 1047-3637 in the medium inoculation density and 2127-3417 in high inoculation density. The very few nematodes recorded in the control treatment could have been due to splash when watering (as all pots were randomized), but considering their low numbers, it is more likely that there has been some minor contamination during the random harvesting procedure. The numbers of females (Fig. 1C) and juveniles (Fig. 1D) followed the same pattern as the total numbers of nematodes, whereas the numbers of males were not different between plant populations in any of the inoculation densities (Fig. 1B).

Males were present in all pots of the experiment, except for both controls, but always in very small proportions $(4.54 \%$ average). Juveniles in different stages and females were proportionally the most abundant $(46.40 \%$ and $49.06 \%$, respectively). The percentage of males was not significantly different between the treatments where nematodes have been inoculated in low, medium and high densities (Table 1). The percentage of juveniles was significantly different between low and medium nematode density treatments.

The multiplication rate $(\mathrm{Pf} / \mathrm{Pi})$ correlated negatively with the initial nematode density $(r=-0.712, p=0.000)$, indicating a decrease in the nematode reproduction with higher densities (Table 2). With the plants from The Netherlands nematodes had a higher multiplication rate in the low and medium densities than with Portuguese plants, but not in the highest inoculation density (Table 2).

Plant origin and nematode inoculation density did not influence plant ontogeny and biomass, with some exceptions (Table 3). Shoot fresh weight of the plants from The Netherlands in the low, medium and high density treatments were higher than in plants from Portugal (Anova, $p=0.022$ ) and root dry weight was highest in all Portuguese plants, independent of inoculation treatment (Kruskal-Wallis, $p=0.008$ ).

\subsection{Cross-inoculation experiment}

Reproduction of Helicotylenchus n. sp. and H. pseudorobustus was dependent on an interaction between nematode origin, nematode density and plant host when considering total numbers of nematodes $(p=0.013)$. When taking into account males, females and juveniles separately, there was no significant three-way interaction. Numbers of males were influenced by nematode origin $(p=0.000)$ and nematode

Table 2 - Pf/Pi multiplication rates of Helicotylenchus n. sp. populations recovered on Ammophila arenaria plants from Portugal and The Netherlands 16 weeks after inoculation of low (100 nematodes), medium (500 nematodes) and high (1000 nematodes) populations

Nematode initial density

Nematode multiplication rate

\begin{tabular}{lcr} 
& Portuguese plants & Netherlands plants \\
\cline { 2 - 3 } 100 & $7.2 \pm 1.0 \mathrm{~b}$ & $10.3 \pm 1.7 \mathrm{c}$ \\
500 & $2.9 \pm 0.3 \mathrm{a}$ & $5.9 \pm 0.4 \mathrm{~b}$ \\
1000 & $3.0 \pm 0.2 \mathrm{a}$ & $2.6 \pm 0.2 \mathrm{a}$ \\
\hline
\end{tabular}

Different letters indicate significant differences $(p<0.05)$ between treatments for the whole experiment after two-way Anova and Fisher test. 
Table 3 - Ontogeny and plant biomass of Ammophila arenaria plants from Portugal and The Netherlands 16 weeks after inoculation with $0,100,500$ and 1000 nematodes per pot

Plants from Portugal

Plants from The Netherlands

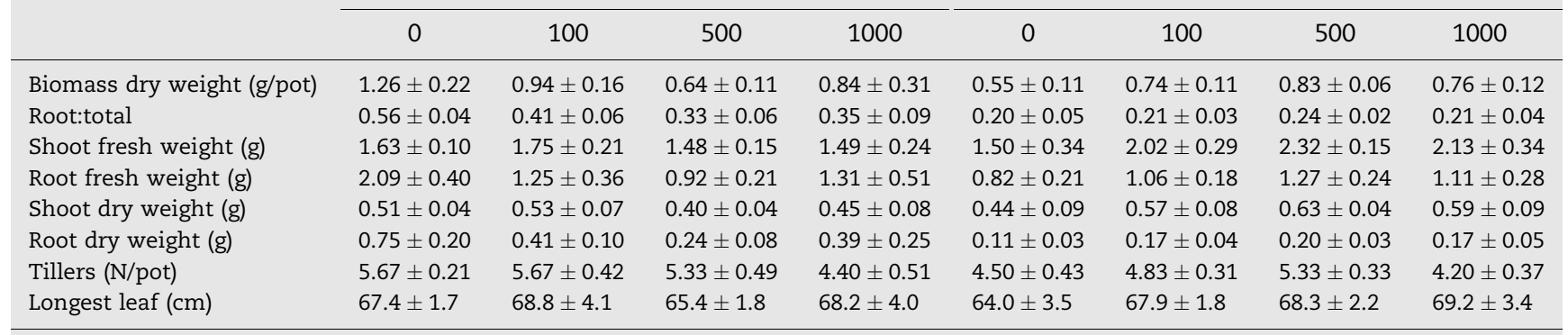

Means \pm S.E.

density $(p=0.002)$, numbers of females by plant origin $(p=0.004)$ and nematode density $(p=0.000)$, and numbers of juveniles by plant origin $(p=0.016)$, nematode origin $(p=0.000)$ and nematode density $(p=0.000)$ (Fig. 2). Total numbers per pot of Helicotylenchus n. sp. from Portugal on A. arenaria plants from The Netherlands were higher than on plants from Portugal. Differences were significant in medium density $(p=0.000)$ (Fig. 2A). Number of male nematodes (Fig. 2B) from Portugal on plants from The Netherlands also tended to be higher, but this was not significant $(p>0.05)$. Number of females (Fig. 2C) of Helictotylenchus n. sp. from Portugal were lower with plants from Portugal, but only in medium nematode density treatment $(p=0.038)$. Juvenile nematodes (Fig. 2D) from The Netherlands reached lower abundance in both low and medium nematode densities than in the high inoculation density treatment. The highest amount was found in Portuguese Helicotylenchus n. sp. with A. arenaria plants from The Netherlands $(p=0.000)$.

H. pseudorobustus produced relatively few males (Fig. 2B). Their numbers were higher in medium density treatments with plants from The Netherlands, whereas the Portuguese plants gave the same, but non-significant pattern. Nematodes from Portuguese cultures were the most abundant, but no differences could be noticed in relation to host plants. Numbers of females were higher in medium nematode density treatment (Fig. 2C). Numbers of females were not different
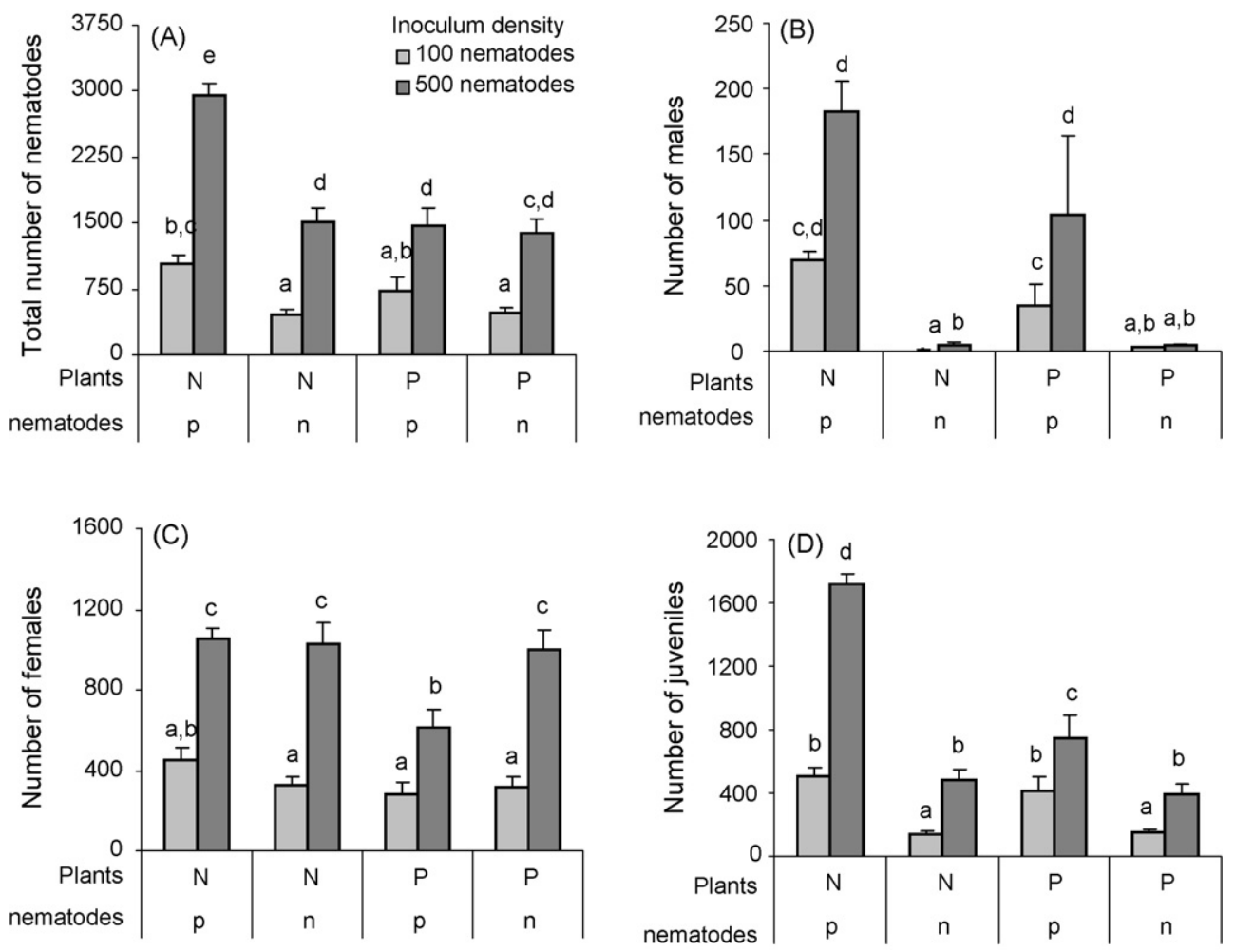

Fig. 2 - Final populations of total (A), males (B), females (C) and juveniles (D) of Helicotylenchus n. sp. (p nematodes) from Portugal and of $H$. pseudorobustus (n nematodes) from The Netherlands recovered on Ammophila arenaria plants from Portugal (P plants) and The Netherlands (N plants) (crossed inoculation) 16 weeks after inoculation with 100,500 and 1000 nematodes per pot. Bars represent means + S.E. Different letters above bars indicate significant differences $(p<0.05)$ between treatments after three-way ANOVA and Fisher's test. 
Table 4 - Percentage of males, females and juveniles of Helicotylenchus n. sp. from Portugal and Helicotylenchus

pseudorobustus from The Netherlands recovered from Ammophila arenaria plants from Portugal and The Netherlands 16 weeks after inoculation with $\mathbf{1 0 0}$ and $\mathbf{5 0 0}$ nematodes per pot

\begin{tabular}{|c|c|c|c|c|c|}
\hline Nematode density & Plants origin & Nematode origin & Males (\%) & Females (\%) & Juveniles (\%) \\
\hline \multirow[t]{4}{*}{100} & Netherlands & Portugal & $6.7 \mathrm{~b}$ & $44.3 \mathrm{a}$ & $49.0 \mathrm{~b}$ \\
\hline & & Netherlands & $0.1 \mathrm{a}$ & $70.8 \mathrm{~b}$ & $29.1 \mathrm{a}$ \\
\hline & Portugal & Portugal & $4.9 \mathrm{~b}$ & $38.8 \mathrm{a}$ & $56.4 \mathrm{~b}$ \\
\hline & & Netherlands & $0.5 \mathrm{a}$ & $67.3 \mathrm{~b}$ & $32.3 \mathrm{a}$ \\
\hline \multirow[t]{4}{*}{500} & Netherlands & Portugal & $6.2 \mathrm{~b}$ & $35.6 \mathrm{a}$ & $58.2 \mathrm{~b}$ \\
\hline & & Netherlands & $0.3 \mathrm{a}$ & $68.1 \mathrm{~b}$ & $31.7 \mathrm{a}$ \\
\hline & Portugal & Portugal & $7.1 \mathrm{~b}$ & 41.9 a & $51.0 \mathrm{~b}$ \\
\hline & & Netherlands & $0.3 \mathrm{a}$ & $71.8 \mathrm{~b}$ & $27.9 \mathrm{a}$ \\
\hline
\end{tabular}

among low inoculation densities. In the medium density, the Portuguese nematodes on Portuguese plants produced lowest numbers of females. Therefore, Helicotylenchus n. sp. produced more females on non-local A. arenaria plants from The Netherlands than on the native host population. Helicotylenchus n. sp. produced more juveniles than $H$. pseudorobustus and again the medium density produced most Helicotylenchus n. sp. juveniles on plants from The Netherlands (Fig. 2D).

Helicotylenchus from The Netherlands had the lowest proportion males and juveniles and the highest proportion females (Table 4). Multiplication rate of both Helicotylenchus species was negatively correlated with nematode initial density $(r=-0.502, p=0.000)$. Biometric parameters of A. arenaria populations from Portugal and The Netherlands were not influenced by plant origin, nematode origin and nematode density treatments $(p>0.05)$.

\section{Discussion}

Helicotylenchus n. sp., which is the dominant nematode species in Portuguese dunes, did not perform better on Portuguese plants than on plants from The Netherlands. H. pseudorobustus, which is a natural non-dominant inhabitant of north-western European dunes, performed equally well on both the local and non-local plant populations of A. arenaria. Therefore, our hypothesis that nematode multiplication would be greater in local than in non-local host plant populations is rejected. Host plant suitability does not explain the occurrence of Helicotylenchus spp. along the north- and south-western European coast. The total nematode reproduction was more influenced by inoculation density than by host plant origin.

Although nematode reproduction was little affected by host plant origin, Helicotylenchus n. sp. and H. pseudorobustus differed in population structure. Helicotylenchus n. sp. had a higher proportion of males and juveniles than $H$. pseudorobustus. This may have been due to the age structure in the cultures used to inoculate the experimental pots, as well as to species-specific characteristics. Helicotylenchus n. sp. also had the highest multiplication rate, independent of density, which could have been due as well to species-specific characteristics, e.g. in life cycle or abiotic preferences, or to age structure in the inoculum. Adjusting these initial conditions will be quite difficult at our experimental scale.
A survey of the plant parasitic nematodes associated with A. arenaria performed in Portuguese coastal sand dunes (Schreck Reis et al., 2005) showed that Helicotylenchus n. sp. was the most abundant plant parasitic nematode. This could indicate a role in A. arenaria decline, since high nematode numbers represent potential damage, indicating some relation to root damage or growth suppression in the plants (Seliskar and Huettel, 1993). However, our inoculation density experiment showed no evidence of negative effects of nematode inoculation on A. arenaria above or below ground biomass. This absence of nematode effects on plant biomass might be explained by the relative short duration of the experiments and the absence of natural abiotic stress factors, such as high temperature and desiccation, which may have prevented plant damage to occur. Alternatively, it may be that this Helicotylenchus species is not involved in decline of A. arenaria in Portugal.

Although present in almost all soils, previous work has pointed out that the damage of Helicotylenchus species is usually insidious rather than dramatic and that only four of the almost 190 species of the genus have been consistently associated with plant growth suppression (Yeates and Wouts, 1992). Studies with A. arenaria in coastal sand dune systems have demonstrated that interactions of other soil biota together with nematodes are probably responsible for negative impact on plants rather than the effect of one or more plant parasitic nematodes alone (Brinkman et al., 2005). Nematode attack could, nevertheless, permit secondary infection by fungi and bacteria (Yeates and Wouts, 1992). Additive interactions between nematodes and soil fungi in the root zone of A. arenaria have been observed for Tylenchorhynchus (formerly Telotylenchus) ventralis (de Rooij-van der Goes, 1995), but synergistic interactions have not yet been observed thus far in this dune grass. More recently, the role of Pratylenchus spp. nematodes have been studied in A. arenaria together with plant associated symbionts. Distinct results were found with arbuscular mycorrhizal fungi that showed to be crucial for control root-feeding nematodes in natural systems (de la Peña et al., 2006) and with endophytic fungus that together with nematodes showed decrease in plant biomass when compared to plants inoculated only with nematodes (Gera Hol et al., 2007).

We conclude that initial densities of Helicotylenchus n. sp. and $H$. pseudorobustus, as well as host plant origin influence nematode multiplication. However, the two nematode species 
did not perform better on their local host plant than on host plants from a distant population. We reject the hypothesis that Helicotylenchus spp. perform better on local than on distant plant populations, although the alternative hypothesis, that non-local plant population is a better host for nematode multiplication was only partly supported. Compared to endoparasitic nematodes such as Meloidogyne, Heterodera or Pratylenchus with which stronger adaptations to host are expected, it is explicable that Helicotylenchus spp. would not have such a close relationship with its potential hosts. In any case, host plant population structure along the north- and south-western European coast does not explain the observed occurrence of Helicotylenchus spp. (van der Putten et al., 2005). The implication of our results for application is that distant or non-native plant populations are not necessarily poor hosts for local nematode populations. Introduction of such plant populations, or new crop races, could keep semi-endo, or ectoparasitic nematode populations at their original level, or they might enhance nematode densities locally. The same might apply to plant populations, which experience range shift due to climate warming.

\section{Acknowledgements}

We thank Célia Santos for the help in field work, Henk Duyts and Roel Wagenaar for culturing H. pseudorobustus, Anna Piśkiewicz for sending The Netherlands nematode cultures, and all the colleagues from the Nematology Laboratory of the Department of Zoology from the University of Coimbra, for the help and use of laboratory facilities.

This work was supported by a PhD grant (BD/970/2000) to CSR from the Portuguese Foundation for Science and Technology (FCT) and by the project POCTI/BSE/42395/2001 from FCT to HF.

\section{R E F E R E N C E S}

Abrantes, I.M.O., Morais, M.M.N., Santos, M.S.N.A., 1978. Nemátodes e plantas hospedeiras identificados em Coimbra, Portugal, durante 1972-1977. Ciência Biológica, Ecology and Systematics 4, 23-44.

Barker, K.R., Olthof, T.H., 1976. Relationships between nematode population densities and crop responses. Annu. Rev. Phytopathol. 14, 327-353.

Bongers, T., 1990. The maturity index: an ecological measure of environmental disturbance based on nematode species composition. Oecologia 83, 14-19.

Brinkman, E.P., van Veen, J.A., van der Putten, W.H., 2004. Endoparasitic nematodes reduce multiplication of ectoparasitic nematodes but do not prevent growth reduction of Ammophila arenaria (L.) Link (marram grass). Appl. Soil Ecol. 27, 65-75.

Brinkman, E.P., Troelstra, S.R., van der Putten, W.H., 2005. Soil feedback effects to the foredune grass Ammophila arenaria by endoparasitic root-feeding nematodes and whole soil communities. Soil Biol. Biochem. 37, 2077-2087.

Cook, R., Yeates, G.W., 1993. Nematode pests of grassland and forage crops. In: Evans, K., Trudgill, D.L., Webster, J.M. (Eds.), Plant Parasitic Nematodes in Temperate Agriculture. $\mathrm{CAB}$ International, Wallingford, UK, $648 \mathrm{pp}$. de la Peña, E., Rodriguez-Echeverria, S., van der Putten, W.H., Freitas, H., Moens, M., 2006. Mechanism of control rootfeeding nematodes by mycorrhizal fungi in dune grass Ammophila arenaria. New Phytol. 169 (4), 829-840.

de Rooij-van der Goes, P.C.E.M., 1995. The role of plant-parasitic nematodes and soil-borne fungi in the decline of Ammophila arenaria (L.) Link. New Phytol. 129 (4), 661-669.

de Rooij-van der Goes, P.C.E.M., van der Putten, W.H., Peters, B.A.M., 1995. Effects of sand deposition on the interaction between Ammophila arenaria, plant-parasitic nematodes, and pathogenic fungi. Can. J. Bot. 73, 1141-1150.

Fernández Prieto, J.A., Fernández-Carvajal, C., Aedo, C., 1987. El género Ammophila host en las costas europeas y norteafricanas. Candollea 42, 399-410.

Firoza, K., MaqBool, M.A., 1994. A diagnostic compendium of the genus Helicotylenchus Steiner, 1945 (Nematoda: Hoplolaimidae). Pak. J. Nematol. 12 (1), 11-50.

Fortuner, R., 1984. Morphometrical variability in Helicotylenchus Steiner, 1945. 6. Value of the characters used for specific identification. Revue de Nématologie 7, 245-264.

Gera Hol, W.H., de la Peña, E., Moens, M., Cook, R., 2007. Interaction between a fungal endophyte and root herbivores of Ammophila arenaria. Basic Appl. Ecol. 8 (6), 500-509.

Hooper, D.J., 1986. Extraction of nematodes from plant material. In: Southey, J.F. (Ed.), Laboratory Methods for Work with Plant and Soil Nematodes. Ministry of Agriculture, Fisheries and Food, London, pp. 51-58.

Huiskes, A.H.L., 1979. Biological flora of the British Isles: Ammophila arenaria (L.) Link (Psamma arenaria (L.) Roem. et Schult; Calamagrostis arenaria (L.) Roth). J. Ecol. 67, 363-382.

Kisiel, M., 1970. On the systematic and geographical distribution of the nematodes inhabiting sand dunes in an Ammophila arenaria plant community. Zeszyty Naukowe Wyszej Szkoly Rolniczej w Szzecinie 34, 151-193.

Little, L.R., Maun, M.A., 1997. Relationships among plant parasitic nematodes, mycorrhizal fungi and the dominant vegetation of a sand dune system. Ecoscience 4 (1), 67-74.

Mukhopadhyaya, M.C., 1974. Studies on the population on Helicotylenchus Steiner (Nematoda: Hoplolaimidae). Revue d'Écologie et de Biologie du sol 11 (2), 233-239.

Oostenbrink, M., 1960. Estimating nematode populations by some selected methods. In: Sasser, J.N., Jenkins, W.R. (Eds.), Nematology. The University of North Carolina Press, Chapel Hill, pp. 85-102.

Orselli, L., Vinciguerra, M.T., 2000. Nematodes of the Sicilian coastal dunes: faunistic and ecological aspects. Boll. Acc. Gioenia Sci. Nat. 358 (33), 171-183.

Rodríguez-Echeverría, S., Freitas, H., van der Putten, W.H., 2008. Genetic diversity and differentiation of Ammophila arenaria (L.) Link as revealed by ISSR markers. J. Coastal Res. 24 (1), 122-126.

Schloter, M., Dilly, O., Munch, J.C., 2003. Indicators for evaluating soil quality. Agric. Ecosyst. Environ. 98, 255-262.

Schreck Reis, C., Freitas, H., van der Putten, W.H., 2005. Plantparasitic nematodes associated with Ammophila arenaria (L.) Link in Portuguese coastal sand dunes. Nematol. Mediterr. 33, 11-18.

Seliskar, D.M., Huettel, R.N., 1993. Nematode involvement in the dieout of Ammophila breviligulata (Poacea) on the MidAtlantic coastal dunes of the United States. J. Coastal Res. 9 (1), 97-103.

Siddiqi, M.R., 2000. Tylenchida-Parasites of Plants and Insects. CABI Bioscience, Egham, UK, 848 pp.

van der Putten, W.H., Troelstra, S.R., 1990. Harmful soil organisms in coastal foredunes involved in degeneration of Ammophila arenaria and Calammophila baltica. Can. J. Bot. 68, 1560-1568. 
van der Putten, W.H., van der Stoel, C.D., 1998. Plant parasitic nematodes and spatio-temporal variation in natural vegetation. Appl. Soil Ecol. 10, 253-262.

van der Putten, W.H., Maas, P.W.T., van Gulik, W.J.M., Brinkman, H., 1990. Characterization of soil organisms involved in the degeneration of Ammophila arenaria. Soil Biol. Biochem. 22 (6), 845-852.

van der Putten, W.H., Yeates, G.W., Duyts, H., Schreck Reis, C., Karssen, G., 2005. Invasive plants and their escape from root herbivory: a worldwide comparison of the root-feeding nematode communities of the dune grass Ammophila arenaria in natural and introduced ranges. Biol. Invasions 7 , 733-746.

van der Putten, W.H., Cook, R., Costa, S., Davies, K.G., Fargette, M., Freitas, H., Hol, W.H.G., Kerry, B.R., Maher, N., Mateille, T., Moens, M., De la Peña, E., Piśkiewicz, A., Raeymaekers, A., Rodríguez-Echeverría, S., van der Wurff, A.W.G., 2006. Nematode interactions in nature: models for sustainable control of nematode pests of crop plants? Adv. Agron. 89, 227-260.

van der Stoel, C.D., van der Putten, W.H., Duyts, H., 2002. Development of a negative plant-soil feedback in the expansion zone of the clonal grass Ammophila arenaria following root formation and nematode colonization. J. Ecol. 90 (6), 978-988.

Wall, J.W., Skene, K.R., Neilson, R., 2002. Nematode community and trophic structure along a sand dune succession. Biol. Fertil. Soils 35, 293-301.

Whitehead, A.G., Hemming, J.R., 1965. A comparison of some quantitative methods of extracting small vermiform nematodes from soil. Ann. Appl. Biol. 55, 25-38.

Yeates, G.W., 1967. Studies on nematodes from dune sands. 9. Quantitative comparison of the nematode faunas of six localities. NZ. J. Sci. 10 (4), 927-948.

Yeates, G.W., 1984. Variation of pasture nematode population over thirty-six months in a summer moist silt loam. Pedobiologia 27, 207-219.

Yeates, G.W., 1987. How plants affect nematodes. In: MacFadyen, A., Ford, E.D. (Eds.), Advances in Ecological Research, vol. 17. Academic Press, London, pp. 61-113.

Yeates, G.W., Wouts, W.M., 1992. Helicotylenchus spp. (Nematoda: Tylenchida) from managed soils in New Zealand. NZ. J. Zool. 19, 13-23.

Yeates, G.W., Bongers, T., de Goede, R.G.M., Freckman, D.W., Georgieva, S.S., 1993. Feeding habits in soil nematode families and genera-an outline for soil ecologists. J. Nematol. 25 (3), 315-331. 